\title{
Mass Budget of Perfluorooctane Surfactants in Lake Ontario
}

\author{
Bryan Boulanger ${ }^{l}$, Aaron M. Peck ${ }^{1,2}$, Jerald L. Schnoor ${ }^{1}$, and Keri C. Hornbuckle ${ }^{l} *$ \\ ${ }^{1}$ Department of Civil and Environmental Engineering, and IIHR-Hydroscience and Engineering, \\ University of Iowa, Iowa City, IA 52240 \\ ${ }^{2}$ National Institute of Standards and Technology, Hollings Marine Laboratory, 331 Fort Johnson \\ Road, Charleston, SC 29412
}

* Author to whom correspondence should be sent

email: keri-hornbuckle@uiowa.edu phone: 319.384.0789 Fax: 319.335.5660 
Perfluorooctane surfactant structures, abbreviations, and names analyzed in this study.

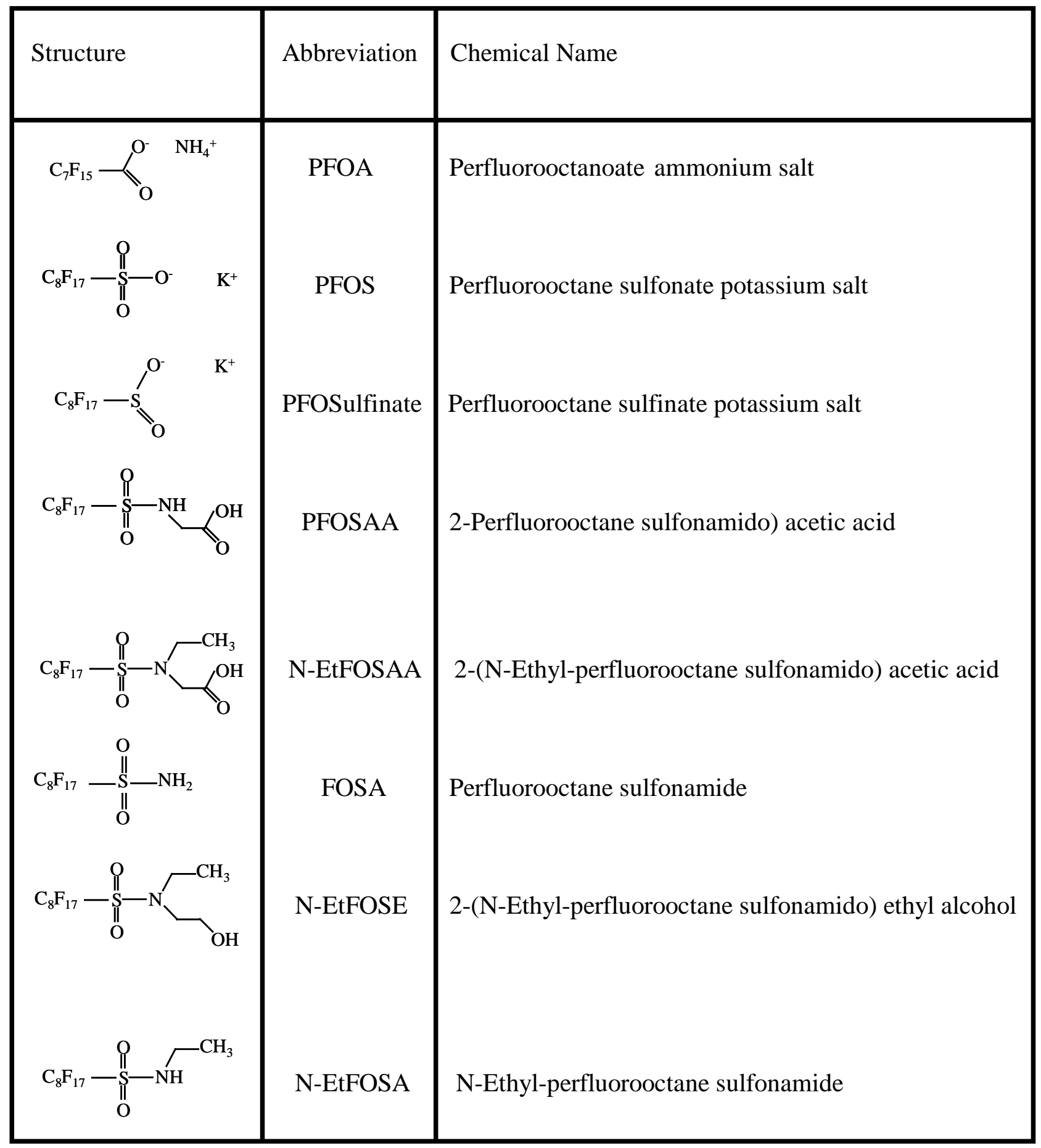

